\title{
IMUNOSSUPRESSÃO NO TRANSPLANTE DE INTESTINO E MULTIVISCERAL - REVISÃO DE LITERATURA
}

\author{
Immunosuppression in Small Bowel and Multivisceral Transplantation - Literature Review
}

\author{
Alisson Paulino Trevizol', Pedro Takata1', Rafael Arruda Pécora², André Ibrahim David²
}

\begin{abstract}
RESUMO
Introdução: Avanços nos protocolos de imunossupressão, diagnóstico precoce e manejo adequado da Rejeição Celular Aguda tornaram viável a realização do Transplante de Intestino Isolado, Multivisceral e Multivisceral Modificado. Objetivo: Analisar os protocolos de imunossupressão dos principais centros de transplante. Método: Revisão de artigos indexados ao PubMed, publicados no período de 2006 a 2012, com foco em receptores adultos. Um total de 211 adultos foi transplantado em sete centros. A imunossupressão foi realizada de três maneiras: Protocolo 1: Indução com Daclizumab e manutenção com Tacrolimus e corticosteróides. Protocolo 2: Indução com Alemtuzumab e manutenção com Tacrolimus. Protocolo 3: Indução com Timoglobulina e Rituximab e Tacrolimus. Resultados: Protocolo 2 teve a menor taxa de rejeição aguda (34\%) e os Protocolos 1 e 3 tiveram 54\% e 48\%, respectivamente. A taxa de sobrevida de um ano foi de 70\%, 79\%, e $81 \%$ nos Protocolos 1,2 e 3, respectivamente. No Protocolo 3, a sobrevida de um ano para transplante de intestino e para transplante multivisceral separadas foi $86 \%$ e 79\%, respectivamente. Conclusão: Protocolo 2 utilizou imunossupressores mais potentes, capazes de reduzir a taxa de rejeição celular aguda, no entanto, apresentou menor taxa de sobrevida de um ano, possivelmente devido a um aumento de sepse grave devido à imunossupressão mais forte. O Protocolo 3 apresenta-se aparentemente como a melhor opção, com sobrevidas superiores.
\end{abstract}

Descritores: Transplante; Imunossupressão; Intestino Delgado; Rejeição de enxerto.

Instituições:

${ }^{1}$ Acadêmico de Medicina da Faculdade de Ciências Médicas da Santa Casa de São Paulo, São Paulo, Brasil.

${ }^{2}$ Departamento de Gastroenterologia, Disciplina de Transplante de Fígado e Órgãos do Aparelho Digestivo da FMUSP.

\section{Correspondência:}

\section{André Ibrahim David}

Rua Pamplona, 1808, apto 52, CEP 01405-002, São Paulo/SP, Brasil. Tel: 3663-2595

E-mail: andredavidmd@gmail.com

\section{INTRODUÇÃO}

O transplante de intestino (TI) é o único tratamento curativo para pacientes com falência do trato intestinal com complicações que ameaçam a vida devido à nutrição parenteral. $\mathrm{O}$ primeiro transplante de intestino foi realizado em 1964 no Boston Floating Hospital. ${ }^{1}$ Após 20 anos, o primeiro transplante multivisceral (TMV) foi realizado pela Universidade de Pittsburgh. ${ }^{2}$ De acordo com o relatório anual de 2010 do Organ Procurement and Transplantation Network ${ }^{3}$ (OPTN), de 1998 a 2009, o número de novos pacientes listados para TI ou TMV triplicou, de 38 para 114. O número de transplantes foi de 70 para 180 , passando de 28 para 81 o número de TIs e de 42 para 89 o número de TMVs.

No início, os protocolos de imunossupressão incluíam a ciclosporina, e a rejeição do enxerto e infecção grave impossibilitavam o progresso do procedimento. Este tornou-se viável com o advento do Tacrolimus em 1989. ${ }^{4}$ A expressão de antígenos de histocompatibilidade no intestino, micro-organismos e células imunológicas residentes, e a defesa imunológica inata tornavam a rejeição ao enxerto e infecção problemas maiores do que no transplante de outros órgãos sólidos. ${ }^{5,6}$ As taxas de sobrevida de pacientes e enxertos elevaram-se após a introdução da terapia de indução, que reduz a necessidade de altas doses de Tacrolimus e diminui as taxas de Rejeição Celular Aguda (RCA). No entanto, complicações relacionadas à infecção mantêm-se o principal fator de óbito de receptores devido à forte imunossupressão.? A chave para um adequado protocolo de imunossupressão é atingir o equilíbrio entre a RCA e a taxa de infecção. 


\section{OBJETIVO}

Analisar os resultados segundo protocolo de imunossupressão dos principais centros de transplante publicados nos últimos cinco anos.

\section{MATERIAL E MÉTODOS}

Realizamos uma revisão no PubMed, focando em protocolos de imunossupressão no TI e TMV em receptores adultos. Selecionamos artigos de 2006 a 2011. ${ }^{8-13}$ Os critérios de seleção incluíam artigos com informações sobre o protocolo de imunossupressão utilizado. Três diferentes protocolos foram comparados: (Protocolo 1) Daclizumab $(2 \mathrm{mg} / \mathrm{kg} / \mathrm{semana}$ por três meses e $1 \mathrm{mg} / \mathrm{kg} / \mathrm{semana}$ por outros três meses) como indução e manutenção com Tacrolimus $(15-20 \mathrm{ng} / \mathrm{dL})$ e corticosteróides. (Protocolo 2) Alemtuzumab $(0,3$ $\mathrm{mg} / \mathrm{Kg}$ em quatro doses no dias $0,1,3,7$ de pós-operatório) como indução e manutenção com Tacrolimus (8-12 ng/mL) e (Protocolo 3) Timoglobulina (ATGr $10 \mathrm{mg} / \mathrm{Kg}$ divididos em cinco doses equivalentes de $2 \mathrm{mg} / \mathrm{Kg}$ nos dias 0, 2, 4, 6 de pós-operatório) e Rituximab (150 mg/ $\mathrm{m} 2$ em dose única no terceiro dia de pós-operatório) como indução e manutenção com Tacrolimus (12-15 ng/dL). As taxas de infecção, RCA e sobrevida do paciente foram comparadas.

\section{RESULTADOS}

Um total de 211 adultos foram transplantados: 74 pacientes no Protocolo 1, 105 no Protocolo 2 e 27 no Protocolo 3.

A Figura 1 mostra a taxa de sobrevida dos pacientes por protocolo de imunossupressão. A Figura 2 mostra a taxa de RCA por protocolo de imunossupressão.

Figura 1 - Taxa de sobrevida do paciente por protocolo de imunossupressão

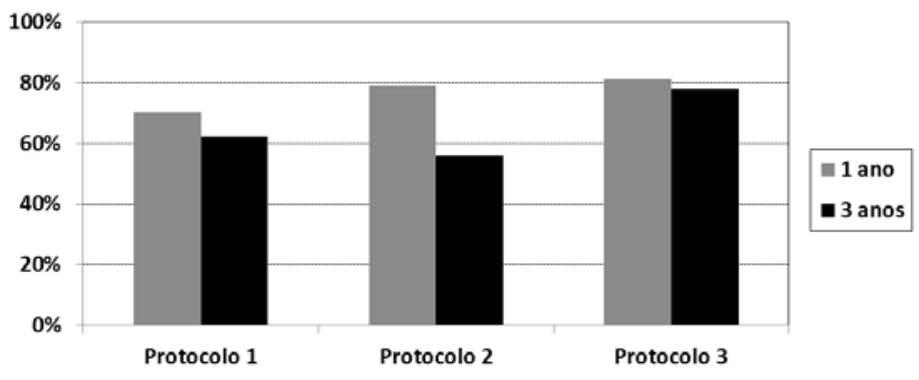

Figura 2 - Taxa de RCA por Protocolo de Imunossupressão

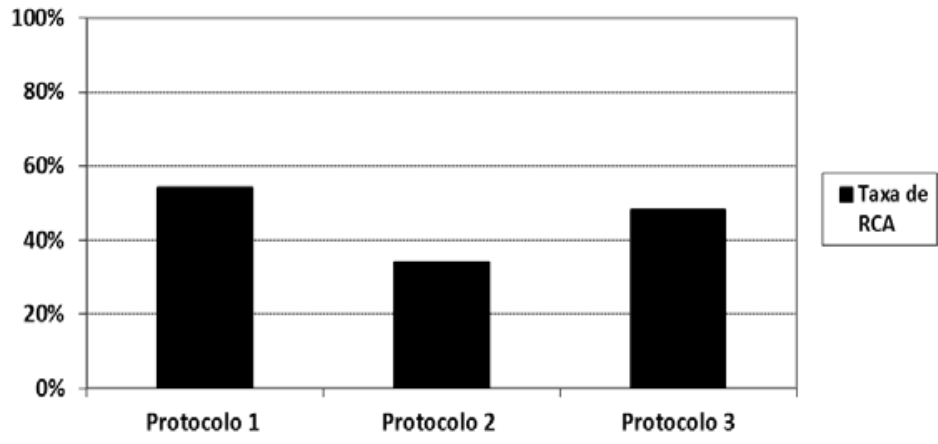

Encontramos que o Protocolo 2 apresentou menor taxa de RCA (34\%). Os Protocolos 1 e 3 tiveram taxas de 54\% e 48\%, respectivamente. A taxa de sobrevida em um ano foi de $70 \%, 79 \%$ e $81 \%$ para os Protocolos 1,2 e 3, respectivamente. Protocolos 1 e 2 apresentaram taxas de infecção grave de $62,5 \%$ e $52 \%$, respectivamente. A taxa de sobrevida em três anos foi de $63 \%, 56 \%$ e 78\% para os Protocolos 1, 2 e 3, respectivamente (Tabelas 1 e 2).
Tabela 1 - Taxa de sobrevida do paciente, por autor e protocolo de imunossupressão.

\begin{tabular}{lccc}
\hline \multicolumn{1}{c}{ Autor } & N & Protocolo & $\begin{array}{c}\text { Taxa de Sobrevida } \% \\
\mathbf{1} / \mathbf{3} / \mathbf{5} \text { anos }\end{array}$ \\
\hline Nishida 2006 & 39 & 1 & $57 / 48 /-$ \\
Nishida 2006 & 37 & 2 & $70 / 47$ - \\
Zanfi 2010 & 12 & 1 & $78 / 76 / 66$ \\
Zanfi 2010 & 28 & 2 & $79 / 50 / 43$ \\
Lauro 2006 & 12 & 1 & $92 / 82 /-$ \\
Lauro 2006 & 17 & 2 & $82 / 64 /-$ \\
Kimura 2008 & 11 & 1 & $80 / 80 / 75$ \\
Kimura 2008 & 23 & 2 & $90 / 70 / 60$ \\
Yuan-Xin 2010 & 5 & 2 & $81 / 78 /-$ \\
Vianna 2008 & 27 & 3 & \\
\hline
\end{tabular}

Tabela 2 - Taxas de Rejeição Celular Aguda (RCA) e infecção, por autor e protocolo de imunossupressão.

\begin{tabular}{lccc}
\hline \multicolumn{1}{c}{ Autor } & Protocolo & $\begin{array}{c}\text { Taxa de RCA \% / } \\
\text { n pacientes / n leve / } \\
\text { n moderada / n grave }\end{array}$ & $\begin{array}{c}\text { Taxa de } \\
\text { infecção \% / n } \\
\text { pacientes }\end{array}$ \\
\hline Nishida 2006 & 1 & - & - \\
Nishida 2006 & 2 & - & - \\
Zanfi 2010 & 1 & $66 / 8 / 9 /-/-$ & $66 / 8$ \\
Zanfi 2010 & 2 & $42 / 12 / 11 / 3 /-$ & $57 / 16$ \\
Lauro 2006 & 1 & $42 / 5 / 6 /-/-$ & $58 / 7$ \\
Lauro 2006 & 2 & $12 / 2 /-/ 2 /-$ & $53 / 9$ \\
Kimura 2008 & 1 & - & - \\
Kimura 2008 & 2 & - & - \\
Yuan-Xin & 2 & $60 / 3 / 7 / 3 / 1$ & - \\
2010 & 3 & $48 / 13 / 9 / 2 / 8$ & - \\
Vianna 2008 & 3 & &
\end{tabular}

\section{DISCUSSÃO}

A viabilidade do TI e do TMV foram possíveis após os avanços nos protocolos de imunossupressão, particularmente a indução. O relatório anual da OPTN mostra uma redução de RCA precoce de $20 \%$ em 1998 a $8,3 \%$ em 2009. No entanto, RCA permanece muito frequente, com 43,1\% dos pacientes transplantados de 2005 a 2009 apresentando RCA no primeiro ano após o transplante. 3 Enquanto a RCA mantém-se a principal causa de perda de enxerto, tornando necessários elevadas doses de imunossupressores, a incidência de infecções bacterianas permanece alta, sendo a sepse a principal causa de óbito após TI e TMV. ${ }^{14}$

Comparamos três protocolos de imunossupressão utilizados pelos principais centros transplantadores de TI e TMV. O Protocolo 1 inclui Daclizumab como indução, Protocolo 2, Alemtuzumab, com efeito que dura aproximadamente seis meses, e Protocolo 3, com Rituximab e Timoglobulina como indução. Esta apresenta possível efeito protetor contra lesão de reperfusão, demonstrado quando administrada antes do transplante de órgãos sólidos. ${ }^{15-17}$

O Protocolo 2 teve a menor taxa de RCA (34\%), provavelmente devido à forte imunossupressão atingida pelo Alemtuzumab. A taxa de infecção do Protocolo $2(52 \%)$ foi menor do que a do Protocolo 1(62,5\%). Além disso, a taxa de sobrevida de um ano 
foi melhor no Protocolo $2(79 \%)$ do que no Protocolo 1 (70\%), representando provável superioridade do Protocolo 2, com indução com Alemtuzumab, em comparação com o Protocolo 1.

Quando comparamos os Protocolos 2 e 3, encontramos que, apesar da maior taxa de RCA (48\%) no Protocolo 3, com quase metade sendo grave $(42,1 \%)$, apenas $30 \%$ dos episódios ocorreram nos primeiros 90 dias de pós-operatório, principal tempo de ação da indução. Além disso, apenas um paciente de TMV apresentou um episódio de RCA grave, possivelmente devido à remoção de maior quantidade de tecido linfoide nativo e à maior carga celular do TMV (fígado e intestino do mesmo doador).

O TI e o TMV são potencialmente contaminados devido à natureza do procedimento e às complexas patologias abdominais comumente associadas. Além disso, lesão da barreira mucosa intestinal, causada pela preservação do órgão ou por rejeição, eleva o risco de translocação bacteriana e fúngica, com subsequente desenvolvimento de infecções sistêmicos, sobretudo no período de recuperação pós-operatória. ${ }^{18}$

Tzakis et al. ${ }^{19}$ encontraram que o sítio de infecção mais comum dáse na corrente sanguínea e no trato respiratório, seguidos da ferida operatória e cavidade abdominal. Metade das bacteremias estava associada ao local do catéter venoso central (CVC).

Oltean et al. ${ }^{20}$ demonstraram que o CVC foi a principal localização de infecção, seguido pelo trato respiratório, cavidade abdominal e ferida operatória. No entanto, nenhum dos estudos separava sítios de infecção por protocolo de imunossupressão ou tempo de pósoperatório.

Kimura et al., ${ }^{21}$ em 2009, estudaram os principais sítios de infecção e patógenos nos Protocolos 1 e 2. No primeiro mês após o transplante, os principais sítios de infecção eram a ferida operatória e a cavidade abdominal, seguidos de CVC e bacteremia. Os principais agentes infecciosos foram: Escherichia coli e Pseudomonas aeruginosa no Protocolo 1, e Enterococcus, Klebsiella, e Pseudomonas aeruginosa no Protocolo 2. Nos meses subsequentes, os principais sítios de infecção passaram a ser o CVC e bacteremia nos dois protocolos, seguidos de lavado bronco-alveolar no Protocolo $1 \mathrm{e}$ ferida operatória no Protocolo 2. Pseudomonas aeruginosa era o principal patógeno no Protocolo 1, e foram relatados no Protocolo 2: Pseudomonas aeruginosa, Escherichia coli, Staphylococcus aureus e Staphylococcus epidermidis, e outros. Além disso, nos pacientes em que se utilizou o Protocolo 2, o tempo de infecção foi maior, provavelmente devido à forte indução. Quase 100\% dos óbitos no estudo ocorreram devido a complicações infecciosas, incluindo sepse e enterite por citomegalovírus.

Cicalese et al. ${ }^{22}$ propuseram o uso de doadores vivos com grau de parentesco para reduzir as infecções bacterianas após TI. No entanto, os riscos, incluindo síndrome do intestino curto, disvitaminoses, e diarréia devem ser considerados antes de se utilizar doadores vivos, sendo a principal dificuldade captar intestino de comprimento adequado ao receptor e ao mesmo tempo garantir autonomia preservando intestino delgado suficiente no doador. Além disso, não é provado que a utilização de doador vivo reduz o risco de infecções ou garanta melhor sobrevida.

\section{CONCLUSÃO}

O Protocolo 2 obteve melhores resultados na redução das taxas de RCA quando comparado aos outros protocolos. A sobrevida de um e três anos dos pacientes é menor em comparação ao Protocolo 3, possivelmente por sepse grave, devido à forte imonussupressão provocada pelo Alemtuzumab. O Protocolo 3 parece ser o melhor protocolo disponível por reduzir a taxa de RCA e apresentar melhores resultados na sobrevida dos pacientes.

\section{ABSTRACT}

Introduction: Advances in immunosuppression protocols, early diagnosis and appropriate management of Acute Cellular Rejection made Small-Bowel, Multivisceral and Modified Multivisceral Transplantation feasible. Purpose: Analyze major transplantation centers immunosuppression protocols. Methods: Literature review based on PubMed indexed articles, published between 2006 to 2012 , focusing on adult recipients. A total of 211 adults were transplanted in seven transplantation centers. Three immunosuppression protocols were used: Protocol 1: Induction with Daclizumab and maintenance with Tacrolimus and corticosteroids. Protocol 2: Induction with Alemtuzumab and maintenance with Tacrolimus. Protocol 3: Induction with Thymoglobulin and Rituximab and maintenance with Tacrolimus. Results: Protocol 2 had the lowest rate of acute rejection (34\%), while Protocols 1 and 3 had 54\% and 48\% respectively. The survival rate 1 year was $70 \%$, $79 \%$ and $81 \%$ in Protocols 1,2 and 3, respectively. Conclusion: Protocol 2 used a more potent immunosuppressant capable of reducing the level of acute cellular rejection. However, it had a lower one-year patient survival rate, possibly due to severe sepsis agravated by the strong immunosuppression. Protocol 3 seems to be the best protocol, capable of elevating patient survival rate.

Keywords: Transplantation; Immunosuppression; Intestine, Small; Graft Rejection.

\section{REFERÊNCIAS:}

1. Kirkman RL. Small bowel transplantation. Transplantation. 1984;37:429-33.

2. Starzl TE, Rowe MI, Todo S, et al. Transplantation of multiple abdominal viscera. JAMA. 1989;261:1449-57.

3. OPTN Annual Report, 2010. http://www.srtr.org/annual_reports/2010/

4. Starzl TE, Todo S, Fung J, et al. FK 506 for human liver, kidney and pancreas transplantation. Lancet. 1989;2:1000-4.

5. Abu-Elmagd K. The history of intestinal transplantation. In: Nakim NS, Papalois VE, eds. The History of Organ and Cell Transplantation. London: Imperial College Press. 2003;171-93.
6. Abu-Elmagd K, Reyes J, Bond G, et al. Clinical intestinal transplantation: a decade of experience at a single center. Ann Surg. 2001;234(3):404-17.

7. Grant D, Abu-Elmagd K, Reyes J et al. 2003 report of the intestine transplant registry: a new era has dawned. Ann Surg. 2005; 241:607.

8. Nishida S, Levi DM, Moon JI, et al. Intestinal transplantation with alemtuzumab (Campath-1H) induction for adult patients. Transplant Proc. 2006; 38(6):1747-9.

9. Zanfi C, Lauro A, Cescon M, et al. Daclizumab and alemtuzumab as induction agents in adult intestinal and multivisceral transplantation: rejection and infection rates in 40 recipients during the early postoperative period. Transplant Proc. 2010;42(1):35-8. 
10. Lauro A, Amaduzzi A, Dazzi A, et al. Daclizumab and alemtuzumab as induction agents in adult intestinal and multivisceraltransplantation: A comparison of two different regimens on 29 recipients during the earlypost-operative period. Dig Liver Dis. 2007;39(3):253-6. Epub 2007 Feb 1.

11. Kimura $\mathrm{T}$, Lauro A, Cescon $\mathrm{M}$, et al. Impact of induction therapy on bacterial infections and long-term outcome in adult intestinal and multivisceral transplantation: a comparison of two different induction protocols: daclizumab vs. alemtuzumab. Clin Transplant. 2009;23(3):420-5.

12. Yuan-Xin L, Ning L, You-Sheng L, et al. Preliminary experience with alemtuzumab induction therapy combined with maintenance low-dose Tacrolimus monotherapy in small-bowel transplantation in China. Transplant Proc. 2010;42(1):29-34.

13. Vianna RM, Mangus RS, Fridell JA, et al. Induction immunosuppression with thymoglobulin and rituximab in intestinal and multivisceral transplantation. Transplantation. 2008;85(9):1290-3.

14. Jordan SC, Pescovitz MD. Presensitization: The problem and its management. Clin J Am Soc Nephrol . 2006;1:421.

15. Beiras-Fernandez A, Chappell D, Hammer C, et al. Influence of polyclonal anti-thymocyte globulins upon ischemia-reperfusion injury in a non-human primate model. Transpl Immunol. 2006;15:273.
16. Bogetti D, Jarzembowski TM, Sankary HN, et al. Hepatic ischemia/ reperfusion injury can be modulated with thymoglobulin induction therapy. Transplant Proc. 2005; 37: 404.

17. Bogetti D, Sankary HN, Jarzembowski TM, et al. Thymoglobulin induction protects liver allografts from ischemia/reperfusion injury. Clin Transplant. 2005; 19:507.

18. Abu-Elmagd KM, Costa G, Bond GJ, etal. Evolution of the immunosuppressive strategies for the intestinal and multivisceral recipients with special reference to allograft immunity and achievement of partial tolerance. Transpl Int. 2009 Jan;22(1):96-109.

19. Tzakis AG, Kato T, Levi DM et al. 100 multivisceral transplants at a single center. Ann Surg. 2005;242:480.

20.Oltean M, Herlenius G, Gabel M, et al. Infectious complications after mu ltivisceral transplantation in adults. Transplant Proc. 2006;38:2683.

21. Kimura T, Lauro A, Cescon M, et al. Impact of induction therapy on bacterial infections and long-term outcome in adult intestinal and multivisceral transplantation: a comparison of two different induction protocols: daclizumab vs. alemtuzumab. Clin Transplant. 2009;23(3):420-5.

22.Cicalese L, Sileri P, Coady N et al. Proposed protocol to reduce bacterial infectious complications in living related small bowel transplant recipients. Transplant Proc. 2002;34:950. 